\title{
The Effect of Poverty on Child Development and Educational Outcomes
}

\author{
Patrice L. Engle ${ }^{a}$ ANd Maureen M. Black ${ }^{b}$ \\ ${ }^{a}$ California Polytechnic State University, San Luis Obispo, California, USA \\ ${ }^{b}$ University of Maryland Baltimore, Baltimore, Maryland, USA
}

\begin{abstract}
Poverty affects a child's development and educational outcomes beginning in the earliest years of life, both directly and indirectly through mediated, moderated, and transactional processes. School readiness, or the child's ability to use and profit from school, has been recognized as playing a unique role in escape from poverty in the United States and increasingly in developing countries. It is a critical element but needs to be supported by many other components of a povertyalleviation strategy, such as improved opportunity structures and empowerment of families. The paper reviews evidence from interventions to improve school readiness of children in poverty, both in the United States and in developing countries, and provides recommendations for future research and action.
\end{abstract}

Key words: poverty; child development; school readiness; educational outcomes; developing countries

"To build a nation, build a school."

-Amartya Sen, Nobel Prize--winning economist

\section{Introduction}

In 2000, the United Nations Millennium Summit adopted eight Millennium Development Goals to be achieved by 2015. The first two goals, to eradicate extreme poverty and hunger and to achieve universal primary education are intimately related. Poverty limits the chances of educational attainment, and at the same time, educational attainment is one of the prime mechanisms for escaping poverty. Poverty is a persistent problem throughout the world and has deleterious impacts on almost all aspects of family life and outcomes for children. This paper examines the mechanisms through which poverty affects child development and educational outcomes, and interventions that have been effective in improving child development and educational outcomes for families in poverty in both the United States and developing countries.

Specifically, this paper examines: 1) the concepts of poverty and child development; 2) mechanisms through which poverty affects child development and educational outcomes, including family functioning and community processes; 3) programs and policies that have alleviated the negative effects of poverty on children's development and have promoted child development and education; and 4) recommendations for future research, programs, and policies to reduce the negative consequences of poverty and promote univer- sal education. The paper addresses the global effects of poverty and educational outcomes by including findings from both developed and developing countries.

\section{Definition of Poverty}

Several controversies occur in the definition of poverty. The first is whether poverty should be defined in economic terms, or as part of a broader social disadvantage. The economic definition of poverty is typically based on income measures, with the absolute poverty line calculated as the food expenditure necessary to meet dietary recommendations, supplemented by a small allowance for nonfood goods. ${ }^{1}$ However, many poverty researchers use a broader definition suggesting that "poor" means lacking not only material assets and health but also capabilities, such as social belonging, cultural identity, respect and dignity, and information and education. According to Sen, ${ }^{2}$ poverty means capability deprivation. A second difference is that some researchers and policy makers see poverty and poverty escape as primarily due to an individual condition, whereas others focus on the social exclusion factors which prevent groups or categories of peoples from moving out of poverty. ${ }^{3}$ The multiple factors are illustrated in a series of case studies in Voices of the Poor 
by the World Bank. ${ }^{4}$ "Throughout the Voices of the Poor series people vividly describe multiple, interlocking sets of disadvantages that leave them powerless to get ahead. Experiences of ill-being including material lack and want (of food, housing and shelter, livelihood, assets and money); hunger, pain and discomfort; exhaustion and poverty of time; exclusion, rejection, isolation and loneliness; bad relations with others, including bad relations within the family; insecurity, vulnerability, worry, fear and low self-confidence; and powerlessness, helplessness, frustration and anger" (p. 12). ${ }^{4}$

Poverty is a dynamic process, with some families cycling in and out of poverty in a relatively short time, resulting in intermittent rather than persistent poverty. In a study of 30,000 households in India, Peru, and Uganda, Krishna ${ }^{6}$ concludes "Up to one-third of those who are presently poor were not born poor; they have fallen into poverty within their lifetimes, and their descents offset the success stories of those that have managed to climb out of poverty" (p. 165). The analytic model developed to explain mobility out of poverty consists of interaction between two sets of factors: 1) changes in the opportunity structure, consisting of the dominant institutional climate and social structures within which disadvantaged actors must work to advance their interests, and 2) changes in the capabilities of poor individuals or groups to take purposeful actions, that is, to exercise agency. ${ }^{5}$ Agency includes individual assets, such as education and self-confidence, and collective and family assets, such as organization, identity, and having a voice. Much of the discussion in this paper refers to the variables under "agency of the poor," but the structure of opportunities may have equal weight.

\section{Definition of Child Development and Educational Outcomes}

Child development refers to the ordered emergence of interdependent skills of sensorimotor, cognitivelanguage, and social-emotional functioning, which depend on the child's physical well-being, the family context, and the larger social network. ${ }^{7}$ Educational outcomes in this paper include school readiness, retention, drop-out, educational achievement, and years of schooling completed. School readiness refers to skills children need to profit from the educational experiences of formal schooling. ${ }^{8}$ School readiness is generally defined as a broad set of skills that affect children's ability to learn in school: physical health, motor skills, self-care, emotional and behavioral self-regulation, social skills, communication skills, pre-academic skills, attention, and curiosity and motivation to learn, although some argue that it should be limited to literacy and numeracy skills. ${ }^{9}$

\section{Impact of Poverty on Children's Development and Educational Outcomes}

In all countries, poverty presents a chronic stress for children and families that may interfere with successful adjustment to developmental tasks, including school achievement. ${ }^{10}$ Children raised in low-income families are at risk for academic and social problems as well as poor health and well-being, which can in turn undermine educational achievement.

\section{USA}

The association between poverty and children's development and academic performance has been well documented, beginning as early as the second year of life ${ }^{11,12}$ and extending through elementary and high school. ${ }^{13}$ When these risks occur during preschool years, they can have long-lasting consequences. For example, readiness for school on entry to kindergarten sets the trajectory for future success. ${ }^{8}$ School readiness is critical to later academic achievement because differences on school entry have long-term consequences. Lee and Burkman, ${ }^{14}$ found that most American students who start school significantly behind their peers can never close the readiness gap. Rather, the gap tends to widen as they move through school. "School readiness has been shown to be predictive of virtually every educational benchmark (e.g., achievement test scores, grade retention, special education placement, dropout, etc)" (p. 21). ${ }^{8}$ The consequences of early school failure are increased likelihood of truancy, drop out, and unhealthy or delinquent behaviors. ${ }^{8}$ Between 30 and $40 \%$ of children entering kindergarten in the United States are estimated to not be ready for school. ${ }^{8}$

The link between poverty and low academic achievement has been well established. ${ }^{15}$ Low-income children are at increased risk of leaving school without graduating, resulting in inflation-adjusted earnings in the United States that declined 16\% from 1979 to 2005 , averaging slightly over $\$ 10 /$ hour. ${ }^{15} \mathrm{Ev}$ idence from the National Institute of Child Health and Human Development Early Child Care Research Network has shown that children in chronically impoverished families have lower cognitive and academic performance and more behavior problems than children who are not exposed to poverty, partially explained by a lack of stimulating behaviors and home experiences among low-income families. ${ }^{16}$

\section{Developing Countries}

Similarly, in developing countries, children in poverty are at much greater risk of never attending school than wealthier children, and these differences are wide (for example, in a sample of 80 countries, $12 \%$ of children in the top quintile of households 
never attended school, whereas $38 \%$ of children in the poorest quintile never attended school). ${ }^{17,18}$ These differences are more highly related to wealth and mothers' education than to urban/rural residence and gender. ${ }^{17}$ Children raised in poverty also achieve less in school. Analyses show strong positive relationships between socioeconomic status and student achievement across countries, across age levels, and across academic areas of study. ${ }^{17}$ Further, socioeconomic differences in achievement scores, often called socioeconomic gradients exist within most countries, reflecting socioeconomic status-related inequality in educational outcomes. ${ }^{19}$

In spite of the overwhelming effects of poverty on children's education and development, there are many examples of children in low-income families who have thrived ${ }^{20}$ Twin studies have shown the individual variability in adaptation that exists even when two children with the same genetic make-up are raised in the same context. ${ }^{21}$ Adoption studies provide a naturalist experiment of how changes in children's primary context, their family, can alleviate the negative consequences of poverty. For example, studies of Romanian children raised in institutional care for the first 2 years of life and then adopted into middle-income British families have shown that many of the children achieved academic and social scores consistent with U.K. norms. ${ }^{22}$ The resilience whereby some children are spared from the negative effects of poverty may reflect individual differences in how families cope with poverty or are able to buffer their children as well as individual differences in the children themselves.

\section{Poverty and Families}

Families are the primary socializing agents for their children. ${ }^{23}$ In addition to providing basic necessities, such as food, shelter, and clothes, families transmit cultural and educational values and help children adapt to societal demands and opportunities. Early parentchild interactions help children learn regulatory process and socialize them into the rhythm of their family and culture.

As Parker, Greer, and Zuckerman ${ }^{24}$ noted almost two decades ago, children growing up in poverty experience "double jeopardy." Not only are they directly exposed to risks in their homes and communities, including illnesses, crowding and family stress, lack of psychosocial stimulation, and limited resources, but they often experience more serious consequences to risks than children from higher income families. In spite of the attention given to the deleterious effects of

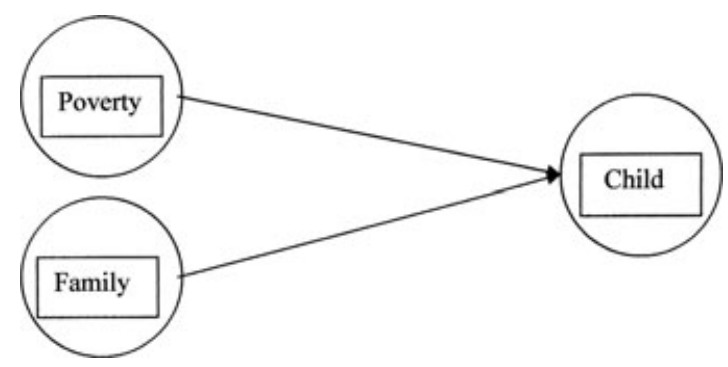

FIGURE 1. Direct effects of poverty on children.

poverty on children over the past several decades, rates of poverty remain high, particularly in families with young children, ${ }^{25}$ and there has been limited attention to the processes whereby poverty impacts children's education and development. One reason for the lack of progress has been an over-reliance on basic models that emphasize the direct effects of poverty, with little attention to the mechanisms linking poverty to children's development.

\section{Developmental Systems Theories}

Developmental systems theories (DST) ${ }^{26,27}$ may be helpful in understanding the multiple mechanisms linking poverty with children's education and development. DST is based on ecological theory and conceptualizes interactions across multiple levels, extending from basic biological processes to interactions at the individual, family, school, community, and cultural levels. As with any systems model, interactions are bidirectional, such that changes in one aspect of the system may affect relations and processes throughout the system.

\section{Mechanisms for the Effect of Poverty on Child Development and Educational Outcomes}

\section{Direct Effects of Poverty}

In a direct effects model, poverty influences children's education and development by increasing risk factors and limiting protective factors and opportunities for stimulation and enrichment (see FIG. 1). For example, children in low-income families are at increased risk for both undernutrition and overweight, often associated with food insecurity. ${ }^{28,29}$

Evidence suggests that many of the effects of poverty on children are influenced by families' behavior. Lowincome families often have limited education, reducing their ability to provide a responsive stimulating environment for their children. ${ }^{30}$ They tend to limit their 


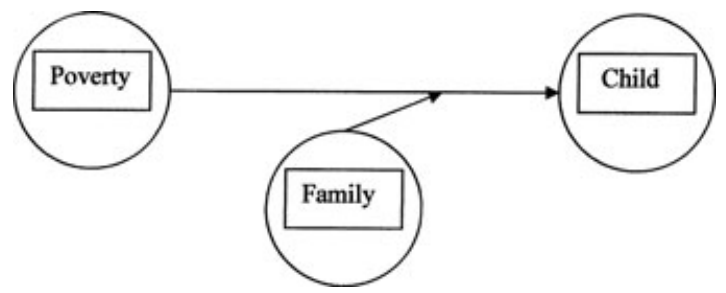

FIGURE 2. Moderated effects of poverty on children.

children's linguistic environment by using language that is dominated by commands and simple structure, rather than by explanations and elaboration with an increase in the percentage of negative comments made. ${ }^{31}$ In addition, low-income families tend to use harsh parenting styles that are based on parental control, rather than reciprocal, interactive styles that promote emotional development and social competence. ${ }^{32}$ Being read to in the first few years of life contributes to the development of phonemic awareness and comprehension skills. ${ }^{50,51}$ However, children from poor families are less likely to be read to than children from better off families. In the United States fewer than half of low income preschoolers are read to on a daily basis, compared with $61 \%$ in families above the poverty line. ${ }^{52}$

\section{Moderated Effects of Poverty}

A moderated effect is one in which the effects of poverty vary across characteristics of families or children (see FIG. 2). For example, families who are poorly educated with poor decision-making skills may have more difficulty protecting their children from the effects of poverty than families who are better educated with rational decision-making skills. ${ }^{33}$ Moderated effects may also operate by conferring protection on children. For example, the Family Investment Model proposes that parents who are better educated or have access to financial resources invest in their children through educationally enhancing materials (such as books) and activities (reading), thus protecting their children from the effects of poverty. Using data from the National Longitudinal Survey of Youth, Bradley and colleagues ${ }^{34}$ demonstrated that families above the poverty line were more likely to engage in cognitively enhancing activities with their children than were families below the poverty line.

Family characteristics may also influence the association between poverty and children's development through a process known as social selection. ${ }^{35}$ The social selection perspective hypothesizes that individual differences in parental traits lead to differences in income and in turn impact on children's development. For example, parents who have prosocial attributes,

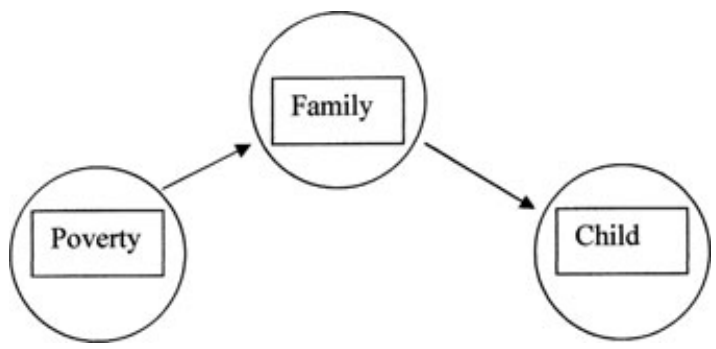

FIGURE 3. Mediated effects of poverty on children.

such as honesty, integrity, and dependability, transmit these values to their children, thus conferring protection even in the face of poverty. ${ }^{36}$

\section{Mediated Effects of Poverty}

In mediated models, the effects of poverty are felt through disruptions in family functioning, which in turn have negative repercussions on the children (FIG. 3). This model was developed through studies of the effects of the Depression of the 1930s on families and on children. ${ }^{37}$ It is consistent with the Family Stress Model, ${ }^{38}$ in which poverty associated with economic hardship may lead to family stress and have a negative impact on parental emotional well-being and mental health, undermining parenting behavior and increasing the likelihood of parents using harsh and controlling parenting. The result has been behavioral and developmental problems for the children. In other words, parents who are stressed and overwhelmed with the pressures of poverty are unable to meet the emotional, cognitive, and caregiving needs of their children. The Family Stress Model has been found to be applicable to families from multi-ethnic backgrounds in the United States ${ }^{39,40}$ and to families from diverse cultures, including Romania ${ }^{41}$ and Indonesia. ${ }^{42}$

\section{Transactional Effects of Poverty}

In transactional models, the effects of poverty reverberate through the relations between families and children, incorporating both moderated and mediated processes (see Fig. 4). Just as parental characteristics may moderate the impact of poverty on children's development, children's characteristics may play a similar role. For example, caregivers of temperamentally difficult children are less likely to exhibit sensitiveresponsive caregiving and more likely to report depressive symptoms than caregivers of temperamentally easy children. ${ }^{43,44}$ The negative consequences of maternal depressive symptoms on children's development are exacerbated in the face of raising a temperamentally difficult child, ${ }^{45}$ and there is likely to be a similar relationship when families are in poverty. Similarly, 


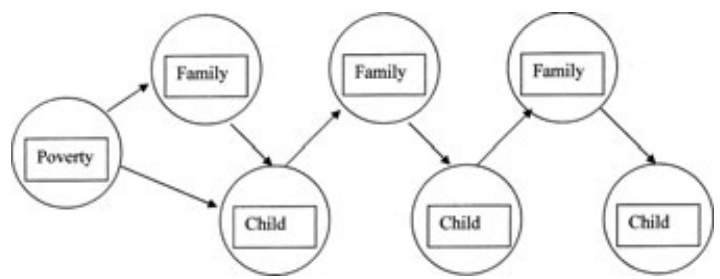

FIGURE 4. Transactional model of the effects of poverty on children.

the Family Investment Model would predict that caregivers are likely to invest in educational resources, even in times of poverty, if they perceive their children to be bright or academically talented.

Thus, although caregivers may experience stress related to poverty, resulting in mental health problems and interfering with the quality of their interactions with their children, they are also influenced by their perceptions of their children's skills and their children's behavior. Likewise, children are influenced by multiple processes. In addition to the direct effects of a lack of resources or other risk factors associated with poverty, there are also negative effects of caregiver behavior, including inconsistent caregiving or harsh parenting, leading to more disorganized child behavior. The cycle continues as caregivers react to their children's more difficult-to-handle behaviors.

\section{Community Influences on Poverty}

DST also highlight the effects of poverty on neighborhood, community, and cultural patterns. Lowincome families tend to live in low-income neighborhoods, often characterized by high density, crime, and few opportunities for academic socialization. ${ }^{46}$ Schools are often under-funded, beset by disciplinary problems, staffed by poorly equipped teachers, and confronted with difficulties meeting their educational mandates. ${ }^{15}$ Despite the apparent importance of community level variables for children's academic performance, they typically account for less variance than family-level variables, ${ }^{47}$ suggesting that, as with the Family Stress Model, the effects of community level poverty may be mediated through family patterns and behaviors.

Movement out of a community of poverty does not necessarily result in the disappearance of the negative effects of persistent poverty. ${ }^{48,49}$ The impact of intermittent poverty on child outcomes is similar to that of persistent poverty. One possible interpretation for the lack of difference between the effects of intermittent and persistent poverty is the Early Effects Model, which suggests that poor behavioral and academic pat- terns established in preschool persist, even if there are improving environmental conditions. ${ }^{13}$ For example, differences in school readiness at school entry have long-term significant associations with school performance, resulting in increasing disparities over time in the United States, ${ }^{14}$ creating gaps that might persist even if a family escapes poverty.

\section{Interventions to Improve Children's Development and Educational Outcomes}

Over the past four decades, there has been convincing evidence that improving school readiness and children's development reduces poverty-related disparities. ${ }^{8}$ In keeping with the models presented above that link poverty with child development, our discussion focuses on interventions that specifically attempt to improve children's school readiness or family support for schooling. These include family-based safety net programs, preschool interventions, programs to improve parents' ability to support early learning, and comprehensive programs that improve children's development prior to school entry. In each case, examples will be provided both from the United States and from developing countries.

\section{USA}

\section{Reducing Family Poverty}

Several macro-level interventions to examine the effects of reducing poverty on children's academic achievement have been evaluated. Initial findings from income supplementation ${ }^{53}$ and residential relocation programs ${ }^{47}$ appeared promising. However, longerterm evaluations of a relatively large residential relocation program in New York illustrate the complexity and variability of the effects of moving children from high-poverty to low-poverty neighborhoods on the academic performance of low-income children. ${ }^{54}$ In this project, one group of low-income children and families received vouchers to move from high-poverty to low-poverty neighborhoods. The initial evaluation $\left(2^{1} / 2\right.$ years after the move) suggested that adolescent boys who moved to low-poverty neighborhoods had better reading and math scores than boys who remained in the high-poverty neighborhoods. There were no differences for girls. However, at the 5-year evaluation, the initial benefits were no longer evident. Rather, there was a reversal of findings. Youth (both genders) in the low-poverty neighborhoods had lower achievement scores than children who remained in high-poverty neighborhoods. There are several possible explanations for the lack of effects, including differential attrition patterns, the disruptions and stress, the persistence of family poverty in spite of changes in neighborhood 
quality, and migration back to the high-poverty neighborhood. There was no change in family economics associated with a move to a low-poverty neighborhood. ${ }^{54}$ These findings illustrate the complexity of trying to alter contextual variables, such as neighborhood and school quality, and suggest that school-age children and families may have established behavioral or learning patterns that are not readily amenable to change.

\section{Developing Countries}

As with the United States, data from developing countries indicate many families experience intermittent poverty, with a smaller percent in persistent poverty. ${ }^{6}$ As in the United States, it is likely that early experiences of poverty would have long-lasting effects even if the family improves its well-being later on in life, but data are not available. Longitudinal studies of changes in poverty suggest that the factors that move families out of poverty may differ from the factors that lead to poverty. One of the most common causes of descent into poverty in many countries is ill health and the costs of health care. ${ }^{5}$ In keeping with the cumulative stress model,${ }^{55}$ one negative experience does not generally plunge a family into poverty, but several successive "blows" may make the difference.

Less is known about factors that help families move out of poverty. ${ }^{56}$ Households in poverty do not usually sit idle, waiting for growth or program benefits to come their way; instead, they adopt strategies to cope with their difficult situations and tide them over until better times. ${ }^{4}$ From initial analysis of the World Bank's Moving out of Poverty case studies, movement out of poverty was associated with increasing diversity of incomes, migration, improved safety nets and services for both informal and formal workers, and education matched with increased opportunities and economic growth. ${ }^{3,6}$ Although some families moved out of poverty due to availability of jobs or formal programs, the percent was small, leading to the conclusion that broadly focused economic programs, or increases in private-sector business have relatively small impacts on poverty escape. ${ }^{3,6}$ Often these programs result in increased disparities because wealthier families are more able to profit from them than poor families.

A new intervention for poverty reduction that is designed to have a specific impact on educational outcomes is the conditional cash transfer programs that give small amounts of funds to household women every month if they are able to meet certain conditions (usually sending children to school and ensuring that children receive minimal nutrition and immunizations). Evaluations in Mexico, Honduras, and Nicaragua have shown significant improvements in children's nutri- tional status as a result of these programs, which should improve school readiness and school attendance, particularly for girls. ${ }^{57-59}$

\section{Improving School Readiness: The Impact of High-Quality Preschool Programs} USA

In developed countries, an increasing body of evidence suggests that providing high-quality preschool experiences, combined with parent involvement and improvement of health status, can have significant effects on children's language and cognitive skills by age 5. Reports of intensive early intervention with disadvantaged children have shown effect sizes of $0.5-0.75$ for the Perry Preschool Project, ${ }^{60}$ the Abecedarian Project, ${ }^{61}$ and the Chicago Child-Parent Centers. ${ }^{62}$

The Perry Preschool Program and the Abecedarian trials are randomized controlled trials of early educational programs that targeted low-income children and showed benefits that extended beyond formal school years into adulthood. ${ }^{60,61}$ The Perry Program began when children were ages 3 and 4 and provided intensive preschool education and home visits for children in poverty. The Abecedarian Project began during the first year of life and provided intensive services to poor and primarily African American mothers and children for 5 years. Both were intensive, high-quality efficacy studies.

The Child-Parent Center Program in Chicago enrolled over 1500 low-income children and provided comprehensive services from kindergarten through third grade as an ongoing program. Longitudinal follow-up has shown that children in the intervention were more likely to graduate from high school, attend college, have fulltime employment, and be enrolled in health insurance, and less likely to have felony arrests, convictions, arrests, or depressive symptoms. ${ }^{62}$ Although these findings are impressive, some caution is warranted because the children were not randomly assigned to the intervention, raising the possibility of selection bias. ${ }^{63}$ However, positive effects have also been found for other state-funded and quality childcare programs, although the effect sizes are lower than for the efficacy trials. ${ }^{64-67}$

Although economists, such as Nobel Laureate James Heckman, ${ }^{68}$ recognize the benefits of investing in early education for both individual children and society, early education has received very little federal support. Recent estimates are that the differences in per capita expenditures for $\mathrm{K}-12$ as compared with prekindergarten are nearly sevenfold. ${ }^{69}$ Rather than focusing on developing preschool programs to ensure school readiness, educational systems often direct their resources 
to reducing the disparities among children already enrolled in school. Yet reading, math, and attentional skills at school entry are predictive of subsequent academic success ${ }^{70}$ suggesting the merits of investments to ensure school readiness in reading, math, and attentional skills prior to school entry.

\section{Developing Countries}

The 30 countries where preprimary education is compulsory are both in developed ${ }^{4}$ and developing countries of these 30 countries, 20 require children to enter at the relatively later ages of 5 or 6 , whereas 10 of the 30 expect them to enter prior to age $5 .{ }^{17}$ Worldwide the number of children enrolled in preprimary education has tripled since 1975 , to $35 \%$ overall. About $75 \%$ of children are attending some form of preschool in industrialized and transition countries, and 32\% in developing countries. Most of these programs are beginning to involve parents, and some incorporate nutrition and health services.

A review of the effects of early child development programs reported in 1992 found that a number of programs appeared to be effective, but many of the evaluation designs were weak. ${ }^{71} \mathrm{~A}$ recent review of evaluations of developing country programs done since 1990 identified eight with adequate designs. In all cases, children enrolled in preschool programs performed significantly better on a variety of cognitive and social outcomes than control children. ${ }^{7}$ For example, in Myanmar and Nepal, a Save the Children preschool program for disadvantaged children resulted in improvements in school entry, retention, and, in Myanmar, cognitive development. ${ }^{7}$

\section{Improving the Family's Capacity to Support Children's Development and Academic Achievement: Parent Education and Support Programs}

Parenting education and support programs are designed to ameliorating the negative effects of poverty on family characteristics, such as lack of responsive stimulation or learning materials, with the goal of improving child well-being. These programs have a variety of delivery mechanisms, including a health center or system, home visiting by a trained worker, combining counseling with growth monitoring, providing group sessions for parents, and media outreach. Some are directed to children with a particular risk factor, such as prematurity or low-birth weight (LBW).

\section{USA}

In the United States, programs for high-risk children have been shown to be effective in improving short-term and long-term outcomes for children.
Sweet and Appelbaum ${ }^{72}$ found improvements in parents' attitudes and behavior and in children's cognitive and socio-emotional development in a meta-analysis of 60 studies. However, effect sizes were often small, raising concerns about the cost-benefits of home visiting programs. A second concern, raised by other studies, is that parenting interventions in high-risk and impoverished populations may not be as effective among families who have the least resources. ${ }^{73}$ In this case, a more comprehensive approach may be needed.

Some successful parenting programs for low-income children are implemented through primary care. Three programs that used randomized control designs have shown beneficial effects on aspects of children's development. Reach Out and Read is a national program in which parents and caregivers are given books at the health visit and encouraged to read to their children. Evaluations have shown beneficial effects on parents' reading behavior and children's language and early literacy skills. ${ }^{74}$ Healthy Steps includes developmental and behavioral advice and risk-factor screening. A recent evaluation showed beneficial effects on parental behavior including health seeking, breastfeeding, television viewing, and injury prevention. However, intervention mothers reported more depressive symptoms than did control mothers. ${ }^{75}$ A third example is a videotaped interaction of the parent and child playing that is reviewed by a child developmental specialist along with the parent. The evaluation showed beneficial effects of the intervention on children's cognitive skills and reduced parenting stress. ${ }^{76}$

\section{Developing Countries}

Sixteen experimental efficacy trials were identified that assessed the impact of cognitive stimulation through parenting on young children from developing countries, including children living in poverty, orphans, and children at medical risk. ${ }^{77}$ For example, in Brazil, 156 low socioeconomic status 13- to 17-month-old infants were assigned to an intervention or control group based on residence area, and their mothers were taught to make toys and engage in activities to promote child development. At 18 months the intervention group had higher scores on the Bayley Scales of Infant Development (BSID) Mental (+9.4 points) and Motor scores $(+8.2$ points) than controls. Differences were stronger for infants with initial BSID scores below $100 .^{78}$ All but one of the 16 studies reported higher cognitive functioning in young children given additional cognitive stimulation or learning opportunities through parenting activities, compared to nonstimulated controls.

A recent review of evaluations of parenting programs (not efficacy trials) in developing countries ${ }^{7}$ 
identified six parent and parent-child programs. Five out of the six evaluations reported significant effects on children's development in comparison with a control group. Successful programs used activity-based learning (being able to practice activities with children rather than just doing them), and demonstrations rather than only discussions, either through home visiting or caregiver group sessions. For example, in Jamaica, healthcare workers visited at-risk homes to show parents how to encourage their children's learning, and significant effects on children's development were found. ${ }^{79}$

In developing countries, health services may be the only contact point with families of children under 3 , and these contact points can be used to evaluate children's development, provide advice to parents on how to encourage development, and address common child-rearing problems. Although over half of all countries have information on child development on mother-held growth cards, the actual use of this information may be limited. ${ }^{7}$ In an attempt to provide a more effective intervention model, the World Health Organization developed the Care for Development module as part of the Integrated Management of Childhood Illnesses. In a trial in an out-patient clinic in Ankara, Turkey, the Care for Development experimental group had significantly higher scores on quality of the home environment than the control group 1 month after a brief intervention. ${ }^{80}$ The authors noted that there were no negative effects on the child's health care or recovery of adding the brief module on development. Although there are many attempts emerging to incorporate information on development into health sector programs, at this point there is a dearth of evidence regarding the effectiveness of these approaches.

\section{Comprehensive Programs: Preschool, Improved Health and Nutrition Services, and Parenting Education and Support}

Comprehensive programs address multiple effects of disadvantage in improving children's development and educational outcomes. Most focus specifically on nutrition and health as well as child development, and many use a variety of strategies including mass media, home visiting, preschool groups, strengthening of healthcare services, and nutrition supplements.

\section{USA}

In the Infant Health and Development Program, a multisite home- and center-based intervention among low-income, LBW infants using a rigorous randomized trial design, there were strong effects of the intervention on children's cognitive skills at age 3 when the intervention ended, ${ }^{81}$ particularly among the heavier
LBW infants. However, when evaluations were conducted at ages 5 and 8 , the benefits were attenuated, and varied by the risk profile of the families. ${ }^{82}$ Children of families with moderate levels of human capital risk had modest, though sustained benefits of the intervention on IQ. Human capital risk was defined by maternal unemployment, welfare receipt, and less than high school education, and moderate risk was defined by one or two of the risks. Families with all three risks may have been too overwhelmed to benefit from the intervention, and families with no risks may have been able to mobilize resources themselves and may not have needed the intervention.

When rigorous designs and evaluations are implemented, some early intervention programs do not have sustained benefits on children's educational attainment. The effects of both the Perry and the Abecedarian Projects were also attenuated when IQ was measured during school age, suggesting that the effects of early intervention may be on learning skills and motivation, rather than IQ per se, and sustained IQ gains may need additional intervention.

The Early Head Start program is another example of an early intervention program designed to promote school readiness and prevent the negative effects of poverty on educational attainment among children prior to age three. In 2004 Early Head Start served 63,000 low-income families across the country through high-quality home visits, child care, case management, parent education, health care, and referrals. A recent evaluation of a randomized trial among 3001 families showed that by age 3, children who participated in Early Head Start were better prepared for preschool than control children, as defined by their cognitive and language development, emotional engagement of the parent, sustained attention with toys, and low rates of aggressive behavior. ${ }^{67}$ In addition, parents of children who received the intervention were more emotionally supportive, more verbal, spent more time reading to their children, and were less likely to spank their children, compared to control parents. These findings highlight the importance of involving parents in the intervention and measuring the impact of the intervention on their behavior and parenting.

Duncan, Ludwig, and Magnuson ${ }^{69}$ have argued for an intensive, early educational program in the United States targeted toward 3- and 4-year-old children as a poverty-reduction strategy. They propose that a highquality, curriculum-driven program, with well-trained and supervised teachers be offered free for low-income children, with a sliding scale available for children of families with more resources. The costs would be 
approximately $\$ 12,000$ /year to include both the halfday educational and half-day childcare components, and they estimate the benefit-cost ratio to be between 4:1 and 7:1, "making it one of the nation's most profitable social investments."70

\section{Developing Countries}

Six evaluations of large-scale programs with acceptable designs that combined interventions to improve nutritional status and child development were identified in a recent literature search. ${ }^{7}$ Five of the six showed impacts on child development. For example, the Philippines Early Child Development Program found significant effects on a developmental test for children who were exposed to a comprehensive set of interventions (feeding, health care, home visits, and child development center) compared to controls, and the effect sizes were largest for those who began earlier and had the longest duration. ${ }^{83}$ The sixth, a World Bank-supported program in Uganda, provided a variety of services, including Child Health Days for immunization and health information, community based projects such as childcare centers, and information for parents on nutrition and how to prepare children for school. ${ }^{84}$ Although there were no effects on a cognitive test administered to children with a mean age of five, significant differences between experimental and control parents were found in parents' beliefs and behaviors about preparing young children for school for children with a mean age of three years. Parents in the intervention group were more likely than control group parents to recognize the importance of their role in school preparation and to change their behaviors to reflect this attitudinal change. ${ }^{84} \mathrm{~A}$ recent report of a large-scale project in Nicaragua ${ }^{85}$ also found significant effects of training mothers to be childcare workers in addition to improved health and nutrition services on children's development. Although it is possible to improve children's readiness for school and influence educational outcomes for poor children, it is unlikely that these effects will be sufficient to reduce poverty without further investments in the opportunity structure for poor and excluded families.

\section{Other Risk Factors in the Context of Poverty}

Most of the research discussed in this paper has addressed economic and social poverty risk and familylevel processes. However, children whose families are poor are far more likely to suffer from conflict, violence, and social unrest than others. As yet, there are relatively few evaluations of effective interventions for ameliorating risks for young children in these difficult circumstances, but this is an area of work deserving immediate attention. In the United States, Evans ${ }^{87}$ has outlined a number of risks related to poverty for American children related to these broader contextual issues. In developing countries, many of these risks are quite common, and many are exacerbated by poverty. TABLE 1 broadly estimates the number of children who face 18 different kinds of risks and the quality of evidence for negative effects of each. ${ }^{86}$

\section{Recommendations for Future Programs and Policies to Improve Children's Development and Educational Outcomes in the Context of Poverty}

Poverty is clearly a risk factor for children's poor development and limited educational outcomes, and it may be that risk in the early years will continue to have an effect even if the family moves out of poverty later in the child's life. Finding ways of reducing poverty is essential for children's healthy development. However, neither education alone nor economic growth alone is likely to be sufficient. World Bank chief economist Nicholas Stern warns that investment-led economic growth alone will not mitigate poverty.

\footnotetext{
We should not think only in terms of economic growth when we try to understand poverty reduction. It is vital that we work to empower poor people to participate in the process. And poverty occurs in many more dimensions than income. Hence, we must also recognize a second pillar in the fight for poverty reduction: empowerment. Empowering poor people so that they can participate in economic growth requires investments in health, in education, and in social protection as well as building institutions that enable them to participate in decisions that shape their lives (p. iii). ${ }^{88}$
}

Thus, interventions are needed that address all aspects of the empowerment framework - more open opportunity structures as well as enhanced individual and collective agency. These changes would have additional effects on children according to DST.

Thus alleviation of poverty demands not only economic solutions, but also the adoption of strategies by governments, communities, and families that alter the deleterious processes whereby poverty limits and disrupts typical development. ${ }^{5}$ Main effects models rarely address the processes linking poverty with child development and should be expanded to include moderated, mediated, and transactional processes inherent in DST. Intervention programs are needed that provide enriching environments and enable children and 
TABLE 1. Risk factors for poor development ${ }^{77,86}$

\begin{tabular}{|c|c|c|c|}
\hline Risk & Prevalence & Effects on children & Strength of Evidence \\
\hline Stunting ${ }^{a}$ & $25-30 \%$ & $\begin{array}{l}\text { 6-13 DQ points, (0.4-0.8 SD), social } \\
\text { and emotional effects }\end{array}$ & Strong \\
\hline Iodine deficiency & $35 \%$ & 9-13 IQ points (1 SD) & Strong \\
\hline $\begin{array}{l}\text { Iron deficiency } \\
\text { anemia }\end{array}$ & $20-30 \%$ & $\begin{array}{l}\text { 1.73 IQ/ } 10 \mathrm{~g} / \mathrm{L} \mathrm{Hb} \text {; Some } \\
\text { supplementation trials show benefits } \\
\text { to motor, social-emotional, and } \\
\text { cognitive development of } 0.3-0.4 \mathrm{SD}\end{array}$ & Strong \\
\hline $\begin{array}{l}\text { Lack of child } \\
\text { stimulation and } \\
\text { learning } \\
\text { opportunities }\end{array}$ & $\begin{array}{l}60-90 \% \text { of parents do } \\
\text { not stimulate }\end{array}$ & $\begin{array}{l}\text { Provision of stimulation/ learning } \\
\text { opportunities has benefits of } \\
0.5-1.0 \mathrm{SD} \text { in IQ }\end{array}$ & Strong \\
\hline Maternal depression & $\begin{array}{l}17 \% \text {, rates may be } \\
\text { higher }\end{array}$ & $\begin{array}{l}0.5 \text { to } 1.0 \mathrm{SD} \text { in cognitive development } \\
\text { scores }\end{array}$ & $\begin{array}{l}\text { Correlations clear; need for treatment } \\
\text { approaches }\end{array}$ \\
\hline $\begin{array}{l}\text { Exposure to violence } \\
\text { and conflict }\end{array}$ & $\begin{array}{l}\text { Major armed conflict } \\
\text { in } 27-38 \% \\
\text { countries from } \\
1990-2003 \text {, affects } \\
20 \text { million children }\end{array}$ & Behavior problems, PTSD & $\begin{array}{l}\text { Urgent need for research particularly } \\
\text { on interventions }\end{array}$ \\
\hline $\begin{array}{l}\text { Intrauterine growth } \\
\text { retardation }\end{array}$ & $11 \%$ & 0.25 to $0.5 \mathrm{SD}$ compared to non-LBW & $\begin{array}{l}\text { Associated with developmental deficits } \\
\text { to age } 3 \mathrm{yr} \text {; need for longitudinal } \\
\text { studies }\end{array}$ \\
\hline Malaria & $\begin{array}{l}40 \% \text { of population in } \\
90 \text { countries- } \\
300-600 \text { million } \\
\text { children }\end{array}$ & $\begin{array}{l}\text { Significant cognitive impairments } \\
\text { associated with severe or cerebral } \\
\text { malaria or number of episodes of } \\
\text { malaria }\end{array}$ & $\begin{array}{l}\text { Negative associations clear; needs } \\
\text { further study }\end{array}$ \\
\hline Lead levels & $40 \%$ & 2-5 IQpoints & $\begin{array}{l}\text { Correlational studies in developed and } \\
\text { developing countries }\end{array}$ \\
\hline Lack of breastfeeding & $40-50 \%$ & $\begin{array}{l}\text { Small effects on cognition (2-5 IQ pts), } \\
\text { may affect bonding }\end{array}$ & $\begin{array}{l}\text { Consistent but small-to-moderate } \\
\text { effects; hard to design good studies }\end{array}$ \\
\hline Parental loss & $\begin{array}{l}\text { Over } 43 \text { million } \\
\text { orphans in } \\
\text { Sub-Saharan } \\
\text { Africa, } 16 \% \text { below } \\
\text { age } 6 \text { ( } 7 \text { million) in } \\
2003\end{array}$ & $\begin{array}{l}\text { Descriptive studies show higher rates of } \\
\text { mortality, some behavior problems, } \\
\text { sense of vulnerability, depression, } \\
\text { improves over time }\end{array}$ & $\begin{array}{l}\text { Need for interventions and } \\
\text { intervention research }\end{array}$ \\
\hline $\begin{array}{l}\text { Lack of maternal } \\
\text { responsivity }\end{array}$ & Unknown & $\begin{array}{l}\text { Associated with less secure attachment, } \\
\text { lower cognitive ability and more } \\
\text { behavior problems }\end{array}$ & Need for more intervention studies \\
\hline Zinc deficiency & $33 \%$ & Cognitive development and activity & Mixed results \\
\hline Intestinal helminths & $33 \%$ & Cognitive development & Inconsistent results \\
\hline HIV Infection & $2 \%$ & $\begin{array}{l}\text { Can be severe; developmental delays, } \\
\text { language delays }\end{array}$ & Evidence for risk is strong \\
\hline Diarrhea & Common & $\begin{array}{l}\text { Some associations with cognitive } \\
\text { development found }\end{array}$ & Suggestive; needs further study \\
\hline Arsenic & $\begin{array}{l}\text { High in areas such as } \\
\text { Bangladesh }\end{array}$ & Lowered IQ & $\begin{array}{l}\text { Correlational data; only investigated in } \\
\text { older children }\end{array}$ \\
\hline Manganese, pesticides & Depends on area & Lowered IQ & Some data but need for more \\
\hline
\end{tabular}

${ }^{a}$ Stunting refers to a height for age score of -2 standard deviations or less below the average height according to recognized norms. DQ, Developmetal quotient; SD, standard deviation; Hb, hemoglobin; PTSD, post-traumatic stress disorder.

families to develop patterns of positive interactions that can be sustained throughout children's education.

Science should inform the most effective early intervention approaches to improve school readi- ness, which would complement economic growth and empowerment. The recent review of strategies to avoid the loss of children's developmental potential among children in developing countries ${ }^{7}$ identified characteristics of successful early child development 
TABLE 2. Characteristics of successful programs and requirements for research
Developing countries ${ }^{7}$
Developed countries ${ }^{63}$

Integration of health, nutrition, education, social, and economic development.

Collaboration with government agencies and civil society

Disadvantaged children

Program intensity and duration

Direct contact with children

Parent involvement

Opportunities for children for initiation and exploration

Traditional child-rearing practices with evidence-based approaches

Staff preparation and support

Attention to quality: structure (e.g., teacher-child ratio, group size) and processes (caregiver warmth and responsiveness)

Improve and evaluate strategies to increase effectiveness of outreach to disadvantaged children, including orphans.

Identify the characteristics of ECD programs that are effective and can be expanded and implemented through existing health, nutrition, education, and social protection services

Examine the role of child development programs in mitigating the effects of poverty

Identify a set of globally accepted measures and indicators for child development to measure program effectiveness

Create and test a method for estimating the costs of models of early child development programs

ECD, early child development.

programs that should form the basis for evidence-based recommendations and identified areas needing additional research. Many of the criteria and recommendations are consistent with issues that Olds ${ }^{63}$ identified that need to be investigated for preschool programs in the United States. The comparison is in TABLE 2.

In both cases, the authors advocate rigorous evaluations of preschool programs, concentrating on wellcontrolled trials in a variety of contexts. Both recommend a high standard of quality, including small teacher-to-child ratios, teacher training and supervision, implementation of an evidence-based curriculum, and enough intensity and duration to ensure that children could achieve goals. Both also recommend that parents be involved and that programs be integrated into national systems of education or health.

In summary, poverty reduction requires a life-cycle approach that begins during the early years before formal schooling to ensure school readiness, involves the family and other proximal contexts, and focuses on the indirect processes linking poverty to child development and educational outcomes. There are no magic bullets that can be applied across all settings. Both individual characteristics and contextual factors determine how children can benefit from educational opportunities and over the course of time, escape from poverty. ${ }^{89}$

\section{Conflicts of Interest}

The authors declare no conflicts of interest.

\section{References}

1. Ravallion, M. 1992. Poverty Comparisons: A Guide to Concepts and Methods. Living Standards Measurement Study Working Paper 88, World Bank, Washington.

2. Sen, A. 1995. The Political Economy of Targeting. In Public Spending and the Poor: Theory and Evidence. D. van de Walle \& K. Nead, Eds.: 11-24. Johns Hopkins University Press. Baltimore.

3. Tilly, C. 2007. Poverty and the politics of exclusion. In Moving Out of Poverty Volume 1: Cross-Disciplinary Perspectives on Mobility. Palgrave MacMillian and The World Bank. Washington, DC.

4. Narayan, D. \& P. Petesch. 2002. Voices of the Poor: From Many Lands. Oxford University Press for the World Bank. New York.

5. NARAyan, D. \& P. Petesch. 2007. Agency, opportunity structure and poverty escapes. In Moving Out of Poverty: CrossDisciplinary Perspectives on Mobility. D. Narayan \& P. Petesch, Eds.: Palgrave MacMillian and The World Bank. Washington, DC.

6. KrishnA, A. 2007. Escaping poverty and becoming poor in three states of India, with additional evidence from Kenya, Uganda, and Peru. In Moving Out of Poverty: Cross-Disciplinary Perspectives on Mobility. D. Narayan 
\& P. Petesch, Eds.: Palgrave MacMillian and The World Bank. Washington, DC.

7. Engle, P. et al. 2007. Strategies to avoid the loss of developmental potential in more thatn 200 million children in the developing world. Lancet 369: 229-242.

8. Zigler, E., W. Gilliam \& S. Jones. 2006. A Vision for Universal Preschool Education. Cambridge University Press. New York.

9. Pianta, R. \& M. Cox. 1999. The Transition to Kindergarten. Paul H. Brooks. Baltimore.

10. McLoyd, V.C. \& L. WiLson. 1990. Maternal behavior, social support, and economic conditions as predictors of distress in children. New Dir. Child Dev. 46: 49-69.

11. Black, M.M., C. Hess \& J. Berenson-Howard. 2000. Toddlers from low-income families have below normal mental, motor, and behavior scores on the revised Bayley scales. J. Appl. Dev. Psychol. 21: 655-666.

12. Campbell, F.A. et al. 2001. The development of cognitive and academic abilities: growth curves from an early childhood educational experiment. Dev. Psychol. 37: 231242.

13. Entwisle, D., K. Alexander \& L. Olson. 2005. First Grade and Educational Attainment by Age 22: A New Story. Am. J. Sociol. 110: 1458-1502.

14. LEe, V.E. \& D.T. Burkman. 2002. Inequality at the starting gate: Social background differences in achievement as children begin school. Econonomic Policy Institute. Washington, DC.

15. Murnane, R.J. 2007. Improving the education of children living in poverty. Future Child 17: 161-182.

16. National Institute of Child Health and Human Development Early Child Care Research Network. 2005. Duration and developmental timing of poverty and children's cognitive and social development from birth through third grade. Child Dev. 76: 795-810.

17. EFA Global Monitoring Report Team. 2006. EFA Global Monitoring Report 2007: Strong foundations: Early childhood care and education. UNESCO. Paris.

18. Bruneforth, M. 2006. Characteristics of children who drop out of school and comments on the drop-out population compared to the population of out-of-school population. Background paper for EFA Global Monitoring Report 2007.

19. Ross, K., L. Zuze \& D. Ratsatsi. 2005. The use of socioeconomic gradient lines to judge the performance of school systems. Paper presented at SACMEQ Research Conference, Paris, Sept 28-Oct 2.

20. Luthar, S., D. Cicchetti \& B. Becker. 2000. The Construct of resilience: a critical evaluation and guidelines for future work. Child Dev. 71: 543-562.

21. Carbonneau, R. et al. 2002. Assessment of genetic and environmental influences on differential ratings of withinfamily experiences and relationships in twins. Psychol. Med. 32: 729-741.

22. RutTer, M. 1998. Developmental catch-up, and deficit, following adoption after severe global early privation. English and Romanian Adoptees (ERA) Study Team. J. Child Psychol. Psychiatry 39: 465-476.

23. Repetti, R.L., S.E. Taylor \& T.E. Seeman. 2002. Risky families: family social environments and the mental and physical health of offspring. Psychol. Bull. 128: 330 366.

24. Parker, S., S. Greer \& B. Zuckerman. 1988. Double jeopardy: the impact of poverty on early child development. Pediatr. Glin. North Am. 35: 1227-1240.

25. Trends, G. 2006. Assessing the Educational Indicators in the Kids Count Data Book. Annie E Casey Foundation. Baltimore.

26. Bronfenbrenner, U. 1994. Ecological models of human development. In Effects on Child and Adolescent Development, Vol. 2nd edtn: 1643-1647. Elsevier Science. New York.

27. SAmeroff, A. 2000. Ecological perspectives on developmental risk. In WAIMH Handbook of Infant Mental Health, Vol. 4. J. Osofsky \& H. Fitzgerald, Eds.: 4-33. Wiley. New York.

28. Cook, J.T. et al. 2006. Child food insecurity increases risks posed by household food insecurity to young children's health. J. Nutr. 136: 1073-1076.

29. Casey, P. et al. 2005. Child health-related quality of life and household food security. Arch. Pediatr. Adolesc. Med. 159: $51-56$.

30. Coleman, J. 1990. The Foundations of Social Theory: 1014 Harvard University Press. Cambridge, MA.

31. Hart, B. \& T. Risley. 1995. Meaningful differences in the Everyday Experience of Young American Children. Earlbaum. New York.

32. Steinberg, L., J.D. Elmen \& N.S. Mounts. 1989. Authoritative parenting, psychosocial maturity, and academic success among adolescents. Child Dev. 60: 1424-1436.

33. ShIPLER, D. 2005. The Working Poor: Invisible in America. Alfred A. Knopf. New York.

34. Bradley, R., L. Whiteside \& D. Mundfrom. 1994. Early Indications of Resilience and Their Relation to Experiences in the Home Environments of Low Birthweight, Premature Children Living in Poverty. Child Dev. 65: 346-360.

35. Conger, R.D. \& M.B. Donnellan. 2007. An interactionist perspective on the socioeconomic context of human development. Annu. Rev. Psychol. 58: 175-199.

36. Mayer, R. 1997. Bright futures ahead. Matern. Child Health J. 1: 195-197.

37. Elder, G. \& A. Caspi. 1988. Economic stress in lives: developmental perspectives. J. Soc. Issues 44: 25-45.

38. Conger, R.D. 2002. Resilience in Midwestern families: selected findings from the first decade of a prospective, longitudinal study. J. Marriage Fam. 64: 361-373.

39. Dodge, K.A., G.S. Pettit \& J.E. Bates. 1994. Socialization mediators of the relation between socioeconomic status and child conduct problems. Child Dev. 65: 649 665.

40. Gutman, L. \& V. McLoyd. 2005. Financial strain, neighborhood stress, parenting behaviors, and adolescent adjustment in urban African American Families. J. Customer Serv. 15: 425-449.

41. Robila, M. \& A. Krishnakumar. 2005. Effects of economic pressure on marital conflict in Romania. J. Fam. Psychol. 19: $246-251$.

42. Zevalkink, J. \& J. Riksen-Walraven. 2001. Parenting in Indonesia: inter-and intracultural differences in mothers' 
interactions with their young children. Int. Soc. Study Behav. Dev. 25: 167-175.

43. HYDE, J.S. et al. 2004. Children's temperament and behavior problems predict their employed mothers' work functioning. Child Dev. 75: 580-594.

44. WAChS, T.D. \& J.E. BATES. 2001. Temperament. Blackwell. Malden, MA.

45. BLACK, M. et al. 2007. Depressive symptoms among rural Bangladeshi mothers: Implications for infant development. J. Child Psychol. Psychiatry 48: 764-772.

46. Black, M. \& A. Krishnakumar. 1998. Children in lowincome, urban settings: Interventions to promote mental health and well-being. Am. Psychol. 53: 635-646.

47. Leventhal, T. \& J. Brooks-Gunn. 2000. The neighborhoods they live in: the effects of neighborhood residence on child and adolescent outcomes. Psychol. Bull. 126: 309-337.

48. Ackerman, B.P., E.D. Brown \& C.E. Izard. 2004. The relations between persistent poverty and contextual risk and children's behavior in elementary school. Dev. Psychol. 40: $367-377$.

49. Ackerman, B.P. et al. 2007. Relation between reading problems and internalizing behavior in school for preadolescent children from economically disadvantaged families. Child Dev. 78: 581-596.

50. Pfannenstiel, J., V. Seitz \& E. Zigler. 2002. Promoting school readiness: the role of the Parents as Teachers Program. NHSA Dialog, 6, 71-86.

51. Show, M., Burns \& P. GRigGin. 1998. Preventing reading difficulties. Committee on the Prevention of Reading Difficulties in Young Children, Commission on Behavioral and Social Sciences and Education, National Academy Press. Washington, DC.

52. Federal Interagency Forum on Child and Family Statistics. 2002. America's children: Key national indicators of wellbeing, 2002. US Government Printing Office. Washington, DC. www.childstats.gov/ac2002/index.asp.

53. Gennetian, L.A. \& C. Miller. 2002. Children and welfare reform: a view from an experimental welfare program in Minnesota. Child Dev. 73: 601-620.

54. Leventhal, T., R.G. Fauth \& J. Brooks-Gunn. 2005. Neighborhood poverty and public policy: a 5-year followup of children's educational outcomes in the New York City moving to opportunity demonstration. Dev. Psychol. 41: $933-952$.

55. Sameroff, A. \& B. Fiese. 2000. Transactional regulation: The developmental ecology of early intervention. In Handbook of Early Childhood Intervention. J. Shonkoff \& S. Meisels, Eds.: 135-159. Cambridge University Press. New York.

56. Narayan, D. \& P. Petesch. 2007. Moving Out of Poverty: Cross-Disciplinary Perspectives on Mobility. Palgrave MacMillian and The World Bank. Washington, DC.

57. Hoddinott, J. \& E. Skoufias. 2004. The impact of PROGRESA on food consumption. Econ. Dev. Cult. Change 53: $37-61$.

58. Behrman, J.R. \& J. Hoddinott. 2005. Programme evaluation with unobserved heterogeneity and selective implementation: the Mexican PROGRESA impact on child nutrition. Oxford Bull. Econ. Stat. 67: 547-569.
59. Gertler, P. \& L. Fernald. 2004. The medium term impact of oportunidades on child growth and development in rural areas of Mexico. Instituto Nacional de Salud Publica. Cuernavaca, Mexico.

60. Schweinhart, L. et al. 2005. Lifetime Effects: The High/Scope Perry Preschool Study through Age 40. Monographs of the High/Scope Educational Research Foundation (No. 14). High Scope Press. Ypsilanti, MI.

61. Campbell, F. et al. 2002. Early Childhood Education: Young Adult Outcomes From the Abecedarian Project. Appl. Dev. Sci. 6: $42-57$.

62. ReYNOLDS, A.J. et al. 2007. Effects of a school-based, early childhood intervention on adult health and well-being: a 19-year follow-up of low-income families [see comment]. Arch. Pediatr. Adolesc. Med. 161: 730-739.

63. OLDS, D. 2007. Improving preschool for low-income children with programmatic randomized controlled trials. Arch. Pediatr. Adolesc. Med. 161: 807-809.

64. VANDELL, D.L. et al. 2005. Activities, engagement, and emotion in after-school programs (and elsewhere). New Dir. Youth Dev. 121-129, 113-124.

65. Peisner-Feinberg, E. 1999. The Children of the Cost, Quality, and Child Outcomes Study Go to School: Technical Report. Frank Porter Graham Child Development Center, University of North Carolina. Chapel Hill.

66. Gilliam, W. \& E. Zigler. 2001. A critical meta-analysis of all impact evaluations of state-funded preschool from 1977 to 1998: implications for policy, service delivery, and program evaluation: Early Childhood Research Quarterly $15,441-473$.

67. Love, J.M. et al. 2005. The effectiveness of early head start for 3-year-old children and their parents: lessons for policy and programs. Dev. Psychol. 41: 885-901.

68. Heckman, J.J. 2006. Skill formation and the economics of investing in disadvantaged children. Science 312: 1900 1902.

69. Duncan, G.J., J. Ludwig \& K.A. Magnuson. 2007. Reducing poverty through preschool interventions. Future Child 17: $143-160$.

70. Duncan, G.J. et al. 2007. School readiness and later achievement. Dev. Psychol. 43: 1428-1446.

71. Myers, R. 1992. The Twelve Who Survive. Routledge/ UNESCO London.

72. Sweet, M. \& M. Appelbaum. 2004. Is home visiting an effective strategy? A meta-analytic review of home visiting programs for families with young children. Child Dev. 75: 1435-1456.

73. Gomby, D., P. Culross \& R. Behrman. 1998. Home Visiting: Recent Program Evaluations. The Future of Children 9: $4-26$.

74. Needlman, R. \& M. Silverstein. 2004. Pediatric interventions to support reading aloud: how good is the evidence? J. Dev. Behav. Pediatr. 25: 352-363.

75. Johnston, B.D. et al. 2006. Healthy steps in an integrated delivery system: child and parent outcomes at 30 months. Arch. Pediatr. Adolesc. Med. 160: 793-800.

76. Mendelsohn, A.L. et al. 2007. Use of videotaped interactions during pediatric well-child care: impact at 33 months on parenting and on child development. J. Dev. Behav. Pediatr. 28: 206-212. 
77. WALKeR, S. et al. 2007. Child development: risk factors for adverse outcomes in developing countries. Lancet 369: 145-157.

78. Eickmann, S.H. et al. 2003. Improved cognitive and motor development in a community-based intervention of psychosocial stimulation in northeast Brazil. Dev. Med. Child Neurol. 45: 536-541.

79. Powell, C. et al. 2004. Feasibility of integrating early stimulation into primary care for undernourished Jamaican children: cluster randomised controlled trial. BMJ 329: 89.

80. ERTem, I.O. et al. 2006. Promoting child development at sick-child visits: a controlled trial to test the effect of the intervention on the home environment of young children. Pediatrics 118: e124 el31.

81. 1990. Enhancing the outcomes of low-birth-weight, premature infants. A multisite, randomized trial. The Infant Health and Development Program. JAMA 263: 3035 3042 .

82. Klebanov, P. \& J. Brooks-Gunn. 2006. Cumulative, human capital, and psychological risk in the context of early intervention: links with IQ at ages 3, 5, and 8. Ann. N.Y. Acad Sci. 1094: 63-82.
83. Ghuman, S. et al. 2006. Children's Nutrition, School Quality, and Primary School Enrollment in the Philippines. Population Council. http://www.unicef.org/earlychildhood/ index_resources.html. New York, NY.

84. Britto, P., P. Engle \& H. Alderman. 2007. Early intervention and caregiving: evidence from the Uganda nutrition and early child development program child and health education. Child Health Educ. 1: 112-133.

85. Verdisco, A. et al. 2007. Integrated Childhood Development Services in Nicaragua. Child Health Educ. 1: 87111.

86. Engle, P.L., S. Grantham-MaGregor, M.M. Black, et al. 2007. How to avoid the loss of potential in over 200 million young children in the developing world. Child Health Educ. 1: 68-87.

87. Evans, G.W. 2004. The environment of childhood poverty. Am. Psychol. 59: 77-92.

88. Stern, N. 2003. Foreword to Pathways Out of Poverty: Private Firms and Economic Mobility in Developing Countries. G.S. Fields \& G. Pfefferman, Eds. Kluwer. Boston.

89. RutTer, M. 2006. Implications of resilience concepts for scientific understanding. Ann. N.Y. Acad. Sci. 1094: 1-12. 